\title{
EL DOCTOR FRANCISCO PÉREZ CASCALES. SU BIOGRAFÍA Y EL CAPÍTULO ODONTOLÓGICO DE SU OBRA
}

\author{
Javier Sanz
}

A Juan Pedro Moreno. In memoriam

Entre las celebridades médicas que han ejercido su profesión en el siglo XVII cabe destacar a quien nos ocupa en este trabajo: el Dr. Francisco Pérez Cascales de Guadalajara, un clásico de la pediatría española que forma parte de la brillante promoción pediátrica de nuestro Renacimiento a la cual, y a cada uno de sus miembros en particular, se han consagrado estudios minuciosos que analizan sus respectivas obras y su influencia en promociones médicas posteriores.

Nos interesa abordar la reconstrucción de la vida y parte de la obra escrita de Pérez Cascales. Lo primero, porque junto a datos biográficos fidedignos se han ido añadiendo otros que perpetúan errores que a estas alturas de ninguna manera pueden ser admitidos. La aportación de nuestras investigaciones pondrá luz, definitivamente, a tanta imprecisión, permitiendo seguir el discurrir biográfico del médico. En cuanto a su obra, la dificultad que representa su traducción al latín hace que, salvo el trabajo de López Piñero y Bujosa Homar, no se hayan contemplado los 
diversos capítulos en toda su extensión. Nos dedicaremos ahora, trayéndolo al castellano, al análisis del contenido odontológico del libro pues nuestra vocación a ello nos conduce.

Biografía del Dr. Francisco Pérez Cascales de Guadalajara

\section{Natural de Buges}

Queriendo ver en el apellido «De Guadalajara» su lugar de nacimiento, quienes se dedicaron al estudio de su persona le creyeron natural de la capital de la provincia (1). Lo cierto es que nació en la pequeña villa de Buges (2) - lugar cercano a Meco, actualmente desaparecido-, como comprueban algunos documentos. Por ejemplo, en el acto de incorporación de los grados de licenciado y doctor a la universidad seguntina aparece "franco perez de guadalaxara natural de bujes diocesis de toledo" (3).

El natalicio debió ocurrir en 1550 ya que en el acto de matriculación en la universidad alcalaína, en el año de 1574 aparece de edad de 24 años (4). El suceso, bien a pesar nuestro, no hemos podido comprobarlo al haberse perdido los libros de registro parroquiales de la época (5).

\section{Estudios}

No hay duda de que Pérez Cascales cursó la medicina en la Universidad de Alcalá pues en sus libros de matrículas aparece, sucesivamente, en los años de 1574 a 1577 (6), de cuya procedencia da fe en el acto de incorporación de sus grados académicos a su homónima de Sigüenza como quedó dicho.

Aunque el grado de Bachiller en Medicina no queda recogido en la obra de Alonso Muñoyerro (11), no debemos pensar que acudiera a otra Universidad a obtenerlo y lo haría en aquel año de 1577 pues en 1611 , año de publicación de su obra, dice

"He estado dedicado a la profesión médica durante 34 años» (7). 
De los de Licenciado y Doctor sí deja constancia este autor, fechándolos en 30 de diciembre de 1579 y 4 de marzo del año siguiente, respectivamente, citándole como Francisco Pérez y su naturaleza Guadalajara (8).

En la universidad cisneriana fue alumno del célebre Juan Gómez de Sanabria - médico de Felipe III-, como advierte en la página 66 del tratado, impregnando el paso por estas aulas su actividad profesional a tenor de lo que se trasluce de la lectura de sus páginas. López Piñero y Bujosa Homar (16) indican muy acertadamente cómo Pérez Cascales, por sus estudios en esta universidad, estaba especialmente influido por el llamado "galenismo hipocratista" que habían encabezado Francisco Valles y Cristóbal de Vega y que, a principios del XVII, mantenía Pedro García Carrero, a quien nuestro autor pretendería suceder en la cátedra de vísperas como se verá después. Esta tendencia se caracterizaba por asumir el galenismo, concediendo gran importancia a la observación clínica, de la que Hipócrates se consideraba modelo, y a los datos anatómicos procedentes de la disección de cadáveres humanos, que se utilizaban para fundamentar o rectificar las teorías tradicionales sobre la patogenia y la ubicación de las enfermedades.

Aspiró, como apuntábamos, a sustituir a Pedro García Carrero, titular hasta 1586 de la cátedra de Vísperas, a la que concurrieron también los doctores Diego Hernández y Garzón. Este impugnó la oposición denunciando un pacto entre Pérez Cascales y Hernández que echaran a suertes quién habría de llevarse la cátedra, abandonando el perdedor. Tras un largo expediente (9) se concedió a Hernández — ganador del ilegal sorteo- que negó el pacto llegando incluso a acusar a Cascales de haber animado a Garzón a presentar la denuncia. El acto de toma de posesión de la cátedra viene a resumir completamente el proceso (10). Desairado por el fracaso, abandonó, de momento, el mundo universitario, pues más adelante obtendría cátedra en la Facultad médica de Sigüenza.

\section{Ejercicio profesional. Médico en Yepes}

Gómez-Menor (11) aporta una referencia en la que dice cómo Pérez Cascales

"desempeñaba el puesto de médico titular de Yepes desde 1587, por escritura pública suscrita en esta villa el 28 de febrero de dicho año. En este concierto con el concejo de Yepes se establece que el contrato durará cuatro 
años, y el médico ha de recibir 40.000 maravedies y 36 fanegas de trigo en grano, cada año».

Debió serle renovada la escritura yá que en 28 de diciembre de 1591 - transcurridos, pues, los cuatro años concertados- hizo testamento encontrándose muy grave, disponiendo incluso se le enterrara en la iglesia parroquial del lugar.

En el documento nombra por herederos a sus hijos Francisco Pérez de Rivera que ingresaría en la carrera eclesiástica-, Rafaela y Sebastiana de Rivera, Luis y'Eufrasia. Su mujer era María de Robledo (11).

No obstante nuestro médico superó la enfermedad y vuelve a dar noticias de su biografía en 3 de febrero de 1595 en que su hija Rafaela ingresa en el convento yepesino de la Madre de Dios. Ahora Pérez Cascales dice ser vecino de la villa de Torrijos (12).

Seguramente, cumplida la segunda escritura por otros cuatro años, pasara a servir a este lugar pues Gómez-Menor (11) cita al Dr. Pedro González como médico titular de Yepes en 1599. ¿Residiría Pérez Cascales en Torrijos al servicio del Duque de Maqueda que le nombró su médico por haber salvado la vida de un hijo suyo, afectado acaso por la epidemia de garrotillo que se desató en aquellos años?

Sabemos cómo era reclamado de otros lugares pues cuenta el episodio en que se vio obligado a intervenir, en Getafe, el 23 de agosto de 1582, por la tenia que expulsó un niño de este lugar (13).

Volvería a Yepes en fecha que desconocemos (desde luego en 1603 se encontraba allí, pues el cabildo catedralicio seguntino contacta con él) completando así los quince años que declara haber sido médico de la villa en la página 10 de su obra.

\section{La etapa seguntina: $1607-1615$ (14)}

El 10 de octubre de 1607, en el cabildo catedralicio de Sigüenza, reunido en pleno, se trataba de la sucesión del Dr. Guevara que, atento a la poca salud de su mujer, había aceptado una oferta de la ciudad de Burgos. Reunidas sus mercedes y

representándose las buenas partes del Dr. Guadalaxara Médico de la villa de Yepes de común acuerdo y consentimiento del dho Cab ${ }^{\circ}$ pleno, sus mds eligie- 
ron por medico desta sancta iglesia al dho Doctorguadalaxara en caso q quiera venir con el salario de quinientos ducados q tenia el Doctor Guebara cada año, y el nombrar persona que vaya por el-dho Medico y darle instruccion de lo q aya de haçer cerca del Concilio que se a de tomar con el dho medico... (15).

Claro es que debió aceptar pues el 22 de mayo siguiente la corporación le concede licencia por diez días para yr a Yepes a un negocio que le importaua (16). Sus obligaciones serían la asistencia médica de los miembros capitulares y sus familiares, así como de los empleados del cabildo. También se encargaría de la atención de los enfermos de los Hospitales de N. ${ }^{\text {a }}$ S. ${ }^{\text {a }}$ de los Remedios y de San Mateo, ambos bajo el patronazgo del cabildo (17).

El primer contrato debió ser de duración de seis años ya que el 9 de febrero de 1613

el Doctor guadalaxara pidió ser oydo, y estando congregadas como lo han de uso y costumbre entro en el dho cabildo y refirio como el tiempo de su officio de Medico se le yba acauando, $q$ suplicaua a sus mds que atendiendo a sus letras y cuidado con $q$ a seruido a todos en gnal y a cada uno en particular se siruiesen de prorrogar el termino por el tiempo q fuesen seruidos (...) salio votado por la mayor parte como se deue y acostumbra haçer q se quede por tal medico por otros dos años más despues de auer cumplido los primeros en $q$ se conçerto con las condiçiones de la primera escritura (18).

Este nuevo período no se cumpliría en su totalidad, como se verá mas adelante.

La etapa seguntina fue brillante para Pérez Cascales pues al mismo tiempo que servía a los intereses de la corporación, obtenía la cátedra de la Facultad de Medicina del Colegio-Universidad de San Antonio de Portaceli (19). Estando vacante, el 20 de noviembre de 1607 se convocaba oposición a la misma compareciendo nuestro médico que quedaba admitido como opositor. Al ser el único:

suplicaba al dho Sor Ror q como a tal unico opositor le mandase dar la poseson de la dha catedra y el dho Sr. Ror auiendo visto ser lo suso dho ansi con parecer de los consiliarios me mando a mi el infra escrito secretario le diese la poseson de la dha Catedra (20). 
La poseería durante el siguiente bienio, al término del cual se convocaría de nuevo. Mientras se realizaba la oposición, quedó el mismo Pérez Cascales como sustituto, presentándose otra vez y volviéndola a ganar en 23 de diciembre de 1609- ya que

fueron todos de pareçer $q$ no auia inconueniente y $q$ asi se le diese la dicha posesion al suso dho Dr Guadalaxara por ser hombre tan bene merito $y$ de tantas $v d s$ (21).

Que era hombre "benemérito" y de "tantas virtudes" no hay duda como lo demuestra el hecho de que siendo vecino de Sigüenza se dio la circunstancia de producirse en dos ocasiones sede vacante por fallecimiento de los prelados Fray Mateo de Burgos y Antonio de Venegas y Figueroa (22) y en ambas resultó elegido Alcalde Mayor de la ciudad (23).

No obstante sus buenas cualidades personales y profesionales, el cabildo no pudo aumentar su salario por lo que Pérez Cascales decidió abandonar el cargo, sin duda teniendo alguna oferta mejor. Así se da cuenta en cabildo de 31 de marzo de 1615 reunido a tal efecto:

estando ansi juntos el señor dean propuso como en el cabildo proxime pasado el doctor Guadalaxara entro en el y pidio y supco. a sus mdes. fuesen seruidos de buscar para El dia de Sant pedro primero venidero medico $q$ les sirva q aunq estaua obligado de seruirles hasta nouiembre venidero recibia particular mrd y fauor que no fuesse obligado sino hasta el dho dia de sant Pedro y quc por su pobreza y atendiendo a la voluntad con que les a seruido a sus mds les suplicaua le mandasen pagar por entero hasta el dho dia digo mes de nouiembre su salario, y auiendose entendido la dha proposicion y conferido todas sus mds nemine discrepante dieron su consentimiento para yr el dho Dr guadalaxara pasado el dho dia de sant pedro y mandaron se le pague su salario enteramente hasta el dho mes de nouiembre primero venidero (24).

¿Cuál fue su nuevo destino? A la edad de 65 años bien pudo ser el definitivo, en que encontrara también su lugar de retirada y descanso, posiblemente cerca de los pueblos donde debutó si bien el dato no puede ser, de momento, confirmado. 


\section{$E l$ "Liber de Affectionibus Pverorvm»}

En 1611 Francisco Pérez Cascales publica su obra dándole por títulu el que sigue:

Liber de affectionibvs pverorvm, vna cvm tractatv de morbo illo vvlgariter Garrotillo appellato, cum duabus Quaestionibus. Altera, De gerentibus vtero rem appetentibus denegatam. Altera vero de Fascinatione. Además, agrega algunos datos propios: Per Doctorem Franciscvm Perez Cascales de Guadalajara Decani, \& Capituli sanctae Ecclesiae Medicum, \& Primarium Medicinae professorem in eadem Univuersitate Seguntina Sigue la fecha, el lugar y la oficina de edición: Anno 1611. Matriti apud Ludouicum Sanchez Typographum Regium. (Ver portada.) .

Consta de casi trescientas páginas, en octavo, y en los preliminares se reflejan la suma del privilegio al autor, la tasa, errata, aprobación del ordinario (Sigüenza, 28 de septiembre de 1610), censura del Dr. Alfonso Valencia de Olivera, médico de Felipe III y del Duque de Lerma, y la dedicatoria al obispo de Sigüenza D. Antonio Venegas y Figueroa - suyas son las armas que luce en la portada-, y al Deán y Cabildo catedralicio seguntino. A continuación, el índice de capítulos, una nómina de autores citados y una canción latina en loor del autor por D. Gómez de Arce. Todo lo anterior precede al texto que se remata con un colofón.

El fundamento del libro lo constituyen los cincuenta capítulos dedicados a las enfermedades de los niños que quedan estructurados ordenándose de la cabeza a los pies (25), no incluyendo nociones de puericultura ni de patología general infantil. El esquema coincide con los de Bagellardo y Rhazes aunque el contenido es diferente, respondiendo a un equilibrio entre teoría - hace gala de una gran formación libresca pues la lista previa de autoridades la componen 62 nombres, entre ellos varios del siglo XVI, contemporáneos sobre todo complutenses- y práctica:

He estado dedicado a la profesión médica durante 34 años y; con el auxilio de Dios omnipotente, he asistido y devuelto a su primitiva salud un número casi incontable de lactantes y de niños que padecián gravísimas y diversas enfermedades (26). 
aduce dejando clara su vocación pediátrica.

Añádense cuatro apéndices: In tractatu de Garrotillo haec quae sequùtur capita continentur, monografía que ha pasado a ser considerada como un clásico del garrotillo o angina diftérica sofocante; Quaestio, vtrûm nulieres vtero, gerentes ob priuationem alicuius cibi ardentes, appetiti, \& denegati possint abortum facere; Quaestio, Vtrûm sanguine misso ex vena, abortiat mulier vtero gerens, cuestiones éstas sobre el ayuno y las sangrías como posibles causas de aborto y In quaestione de fascinatione quaere quae séquuntur, sobre la fascinación o mal de ojo como causante de las enfermedades infantiles, literatura que era muy frecuente en la época.

En el título del presente trabajo queda clara nuestra intención de dedicarnos al análisis del capítulo odontológico de su obra escrita y no es por capricho ni por la encomiable tarea de aportar la traducción de algunas interesantes páginas del texto. El propósito es la búsqueda de los saberes odontológicos que en la centuria se esconden en los tratados generales de medicina y particularmente de cirugía, escaseando de forma alarmante.los textos consagrados a la especialidad. Tan sólo los «intentos docentes» de Alonso Muñoz y Diego Pérez de Bustos, autores de los respectivos Instrucción de los barberos flebotomianos (Valencia, 1621) y Tratado breve, de Flobotomía (Madrid, 1630) aportan algún conocimiento, insuficiente, conscientemente dirigido a la formación de los futuros prácticos de la especialidad: los sangradores, de quienes son ambos «Examinadores Mayores».

Pérez Cascales aborda la patología de la mucosa bucal en el concreto apartado de las aftas, enfermedad que con más frecuencia afecta a los niños así que nacen, de acuerdo a los clásicos Hipócrates, Galeno, Avicena, Celso, Aecio, Pablo de Egina, Guido de Chauliac, Trincabelo y Gordonio, quienes afirman de manera unánime que las Aftas son ulceraciones de la boca que participan de calor ígneo.

Dos serán las causas que motivan su aparición, de un lado la leche viciada de la nodriza y de otro la mala cocción en el vientre del niño, pudiendo ser otras varias caso de presentarse en el adulto. Cuál sea la responsable, se comprueba según el estado de la una y del otro. Si la nodriza se encuentra bien y el niño padece el mal hay que poner manos en el niño y no en la nodriza.

Su diagnóstico, por el tacto y la vista, no ofrece muchas dudas pues además el color de las Aftas es una señal del humor que produce la leche que las origina, conclusión a la que llegan otros tratadistas de la época aunque la coincidencia en las fuentes bibliográficas desmerece la posible 

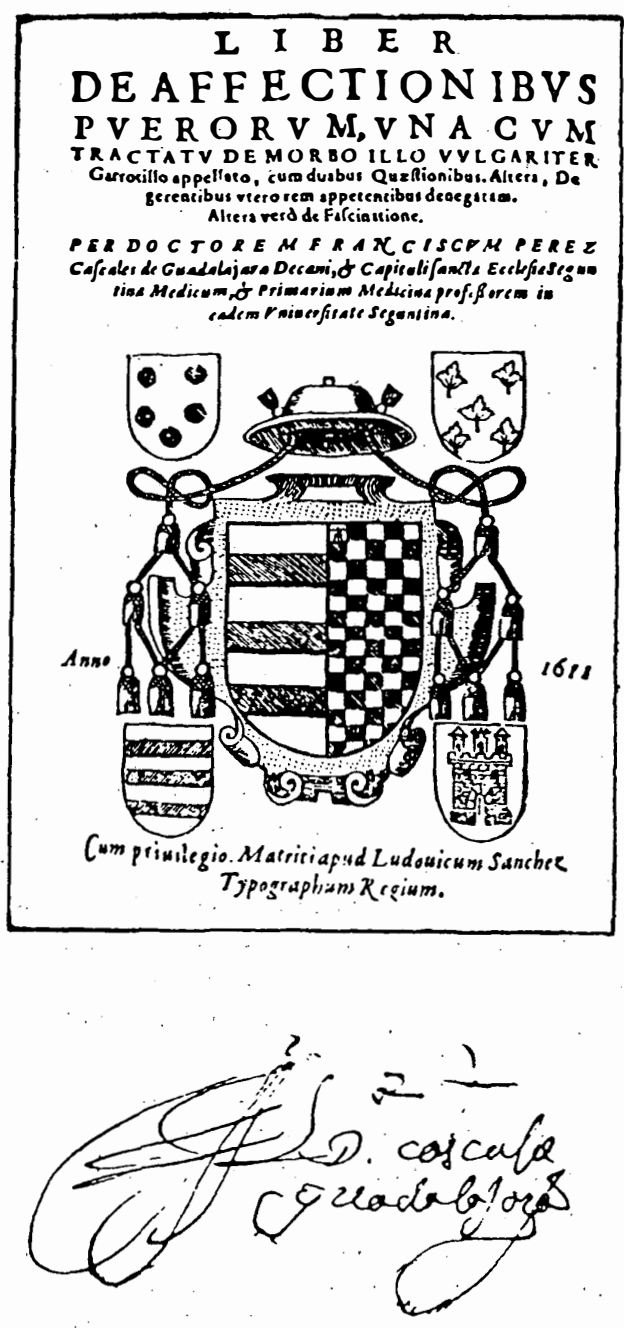

Portada de la obra y firma del Dr. Pérez Cascales 
observación del autor, de forma que si son amarillentas, es excesivo en el cuerpo de la nodriza el humor bilioso; si son blanquecinas, la pituita; si lividas o negras, el melancólico; si rojas, la sangre.

Por último, el tratamiento, una vez precisado su color, se abordará en varios frentes: la pérdida del humor en exceso mediante la realización de sangrías -en puntos bien concretos según qué humor sea responsable-, régimen alimenticio, jarabes que ayuden a la evacuación del humor y lavado de las lesiones con muy elaboradas preparaciones al uso. Ahora bien, si el fallo está en el vientrecillo del niño, además del régimen dietético y las pincelaciones en la herida habrá que frotarle aquél con los elementos caloríficos y corroborantes de sus fuerzas que se detallan. $\mathrm{He}$ aquí la transcripción original del texto.

\section{Capítulo I. Las aftas, o úlceras en la boca de los lactantes (27)}

Siendo muchas las afecciones o enfermedades que suelen atacar a los niños en su primera etapa, en este tratado mencionaré únicamente las más comunes, y trataré de compendiar en unos cuantos capítulos (como manual de principiantes) lo que he encontrado sumamente disperso en las obras de varones de gran autoridad. Comienzo por aquella enfermedad que con más frecuencia afecta a los niñós así que nacen. Hip., Gal., Avicen., Paulo y otros doctísimos autores lá llaman Aftas. Aftas son (según Gal., lib. 6, de comp. med. per loca, cạp. sobre las Aftas) úlceras que aparecen en la superficie de la boca y tienen calor ígneo. Parece confirmarlo Hip. en el lib. 2 de las enfermedades, cuando dice: La fístula de pulmón presenta una úlcera ardiente, que se llama Afta, y en 3 Apho. 24, los niños pequeños y de poco tiempo sufren úlceras en la boca que se denominan Aftas. Avic. en Fen. 6, 3, cap. 23 afirma: Alcola es una úlcera que se produce en la piel de la boca y de la lengua con expansión y dilatación. Alcola es una palabra árabe que vale lo mismo que Afta. Cornel. Cels. en el lib. 2, cap. 1 establece: a infantes y niños pequeños afectan unas úlceras serpenteantes en la boca, que los griegos denominan Aftas. Al mismo mal se refirió Aecio en Tretra. 2, serm. 4, capit. 39, expresándose así: Las ulceraciones que aparecen en la superficie de la boca son llamadas por los griegos Aftas, y presentan un cierto calor ígneo. Paulo en el lib. 1, cap. 10 también parece aludir a lo mismo, cuando dice: La úlcera de la boca, de nombre Afta, se produce en los niños de poco tiempo. Guido, primera figura de la cirugía, aporta una definición o descripción de 
las Aftas prácticamente igual: Se llaman aftas las ulceraciones que se originan en la boca sin pasar de la superficie. Lo mismo Gordonio y todos los demás modernos, como Trincabelo, quien en el lib. 5 de las curas, cap. 6 y 8 afirma: las úlceras interiores de la boca, llamadas por los griegos Aftas y en árabe Alcola, a las que son propensos sobre todo los infantes, participan de un cierto calor ígneo, por lo que son denominadas Aftas. Este vocablo significa quemadura. Así pues, todos cuantos tratan de esta afección, afirman de una manera unánime que las Aftas son ulceraciones de la boca que participan de calor ígneo.

Los signos por los que se puede diagnosticar este mal son tan claros y evidentes que no necesitan explicación: se aprecian por el tacto y la vista. En cuanto a su causa, Gal. en el lib. de comp. med. facul. per locos, cap. sobre las Aftas, parece establecer dos: una, la leche viciada de la nodriza; otra la leche misma no bien cocida en el vientre del niño. Aquí sólo hacemos mención de las causas de las aftas en niños de poco tiempo. En los adultos y mayores existen otras muchas causas, de las cuales ahora no tratamos. Se originan las Aftas, dice Gal. en el lugar citado, ordinariamente en los niños lactantes, o bien por estar viciada la leche de la nodriza, o bien porque el niño no la cuece adecuadamente. Lo mismo repite Aecio 2, tract. 4, cap. 39. Avic. Fen. 6, 3, cap.23. Por lo demás, no siendo una sola la causa de las Aftas, no existe un remedio único, sino diversos según el origen.

En primer lugar, pues, para Gal., pasaje citado 6 de comp. med. per genera, la leche viciada de la nodriza es causa de la aparición de tales úlceras en la boca de los lactantes, úlceras a veces persistentes, difícilmente curables y que con el paso del tiempo adquieren un carácter putrescente.

En segundo lugar se contrae esta afección por corrupción o mala cocción de la leche en el vientrecillo del niño.

Pasemos ya a considerar cuándo se corrompe la leche en los pechos de la nodriza y cuándo en el vientre del niño, para poder actuar metódicamente en la curación. Y con el objeto de que se conozca esto y se comprenda con exactitud, pienso que no es cantar «extra chorum», como suele decirse, exponer aquí brevemente qué es la leche y cómo se produce.

La leche, según Gal., 5 Apho. com. 39, no es otra cosa que una especie de sobrante del alimento de la zona que la produce, semejante a esa zona en su naturaleza. Se origina del modo siguiente. Las mamas, dice Gal., tienen unas glándulas que poseen la capacidad de alterar el alimento que les llega lo convierten en leche; ésta proporciona alimentación y crecimiento al lactante; según la nodriza padezca insalubridad o debilidad, así 
el niño. Igual que lo que crece en la tierra se alimenta de la tierra, y según sea la tierra así recibe, como afirma Hipp. lib. sobre la naturaleza del niño, lo mismo se puede asegurar sobre la leche.

Ahora veamos cómo se corrompe la leche, hasta el punto de convertirse en un pésimo alimento para los lactantes e incluso en causa de Aftas. Que la leche tiene su origen en la sangre nadie debe dudarlo. Dice Galen., 5 de simpli. med. faculta., cap. 21: la leche está entre la pituita y la sangre por lo que a calor se refiere, aunque no a la misma distancia de ambas; dista más de la pituita, y se acerca más a la sangre. Por consiguiente, cuando afluya a los pechos en menor cantidad de la conveniente, y se desee aumentar esta, hay que tener en cuenta la sangre, pues o es la sangre más escasa de lo que debía, o de peor calidad; cuando es más escasa de lo que debía, exige una dieta húmeda y calórica; cuando es de calidad deficiente, si es biliosa necesita una purificación, si es pituitosa requiere medicamentos calóricos. Hasta aquí Gal. Con estas palabras claramente nos enseña que el origen de la leche está en la sangre. Por tanto, si la sangre que nutre y alimenta a la nodriza, es excelente y no participa de ninguna cualidad maligna, producirá en las mamas una leche excelente; si es biliosa, pituitosa o melancólica, la leche producida por ella indudablemente estará viciada. La leche biliosa se torna agria y ardiente; por su parte, la que es más fría de lo normal y la.melancólica causan en los niños enfermedades afines a la leche que maman. Lo deduciremos inmediatamente por el color de las Aftas. Como dice Aecio, tretra. 2, serm. 4, cap 19, las Aftas rojas denotan dominio de la sangre; las amarillentas, de la bilis; las blanquecinas de la pituita; las lívidas y oscuras, dominio de la bilis negra. Igualmente Avicen., Fen. 6, 3, c. 23. Así pues, el color de las Aftas es una buena señal del humor que produce la leche que las origina.

Pueden también originarse las Aftas por un deterioro de la leche producido en el vientre del mismo niño, según aseguran Gal., Avic., Celso y otros gravísimos varones. Y consideramos digno de la máxima atención saber distinguir cuándo las ulceraciones tienen su causa en la leche estropeada o en la enferma de la nodriza, y cuándo en el vientre del niño que la cuece mal. Si el médico no es capaz de diferenciar esto, tampoco podrá llevar a cabo la curación ni prescribir las medicinas rectamente, pues ocurre con muchísima frecuencia que el niño se encuentra afectado y la nodriza goza de excelente salud, o por el contrario, que el sano es el niño, mientras la lactante destila humores morbosos. Lo discernirás como sigue. Si la nodriza tiene buen color, está pronta, ágil y suelta para realizar todas sus actividades tanto animales como naturales, no le duele la cabe- 
za u otras partes del cuerpo, no siente sed o sabor predominante de alguna cualidad, duerme bien, sin desasosiego ni pesadillas, y no percibe dolor, hinchazón o exceso de alguna cualidad en los pechos, si la nodriza se encuentra así y el niño padece úlceras en la boca, hay que poner manos en el niño y no en la nodriza. Aunque, en mi opinión, también a esta habrá que vigilarla; no porque necesite de suyo cura, sino para evitar que sus mamas sufran ulceración por contagio del infante.

Muchas veces los pezones de las lactantes son atacados y ulcerados por el niño tocado de Aftas. Tales.ulceraciones son denominadas "nomae» o devoradoras y serpeantes por Galeno, 6 de comp. pharm. per locos, en el cap. sobre las Aftas, y por Aecio, tratra. 2, serm. 4, cap. 39. Por todo esto, aun cuando la nodriza no padezca enfermedad alguna, su comida y bebida habrán de ser muy cuidadas. Si la nodriza se encuentra como arriba dije, y el lactante al vomitar expulsa leche maloliente, no cabe duda de que es el niño y no la nodriza la causa de las Aftas.

Conocida ya la naturaleza, señales y causas de las Aftas, pasemos a tratar de su curación; en primer lugar, de las que se deben a deterioro de la leche de la nodriza. Y, ante todo, el médico ha de considerar el humor que deteriora la leche. Lo constatará fácilmente si tiene en cuenta las enseñanzas antes citadas de Gal., Paulo y Aecio acerca de los colores de las Aftas. Estos Doctores enseñan expresamente que si son amarillentas es excesivo en el cuerpo de la nodriza el humor bilioso; si son blanquecinas, la pituita; si lívidas o negras, la melancolía; si rojas, la sangre.

\section{Capítulo II. Las Aftas rojas}

La cura de las Aftas o úlceras rojas, las cuales denotan un exceso de sangre en el cuerpo de la nodriza, ha de consistir, ante todo, en una pérdida de sangre. Ahora bien, de qué parte se ha de extraer, no es fácil determinarlo. Unos establecen que de los talones, otros, que de los brazos, yo no desapruebo ni lo uno ni lo otro. Pero, para decidirlo, hemos de averiguar primero si tras el parto la nodriza ha tenido a su tiempo la menstruación o le ha faltado por completo. Si la ha tenido en el tiempo, modo y cantidad debidos, la sangre se sacará de los brazos; si no la ha tenido, o no en la cantidad y orden naturales, la sangre será extraída del talón, en la medida que la enfermedad y las fuerzas la aconsejen; se prescribirán alimentos fríos y húmedos, como lechuga, escarola; la nodriza tomará, de 
carne, pollo, cordero y cabrito. Beberá agua de condrila, de achicoria o de cebada; luego usará jarabe de violetas, de achicoria, de condrila, de membrillos; finalmente se le administrará cañafístula disuelta en agua de leche, de cebada o de condrila. Al mismo tiempo las heridas de la boca del niño se lavarán asiduamente con agua de cebada, de llantén o de verdolaga y un poco de jarabe de rosas, o con una cocción de rosas de acacia y de balaustrias.

Si las úlceras de la boca son amarillentas, parecen reclamar casi el mismo tipo de medicamentos que las rojas, pero más fríos. Y hay que prestar mucha atención a todo el cuerpo de la nodriza: si esta se ve afectada por cacoquimia biliosa, necesita una purgación electuaria. Dicha cacoquimia puede darse juntamente con una exhuberancia; entonces la razón dicta que primero se saque sangre; de qué vena ya se ha indicado anteriormente, cuando hemos hecho referencia a la menstruación. En cuanto a comidas y bebidas guárdese la misma norma que en las úlceras rojas; no obstante, es preferible consumir alimentos más fríos. Tras la extracción de sangre suficiente, si es necesaria, tomará la nodriza los siguientes jarabes durante cinco o seis días, más o menos según exija la purgación del humor, y después, la bebida siguiente, para evacuar el humor nocivo. Jarabes. Toma dos onzas de achicoria, verdolaga, endibia, violetas o condrila; tres onzas de agua de endibias; mezcla. Bebida purgante. Toma cuatro escrúpulos de ruibarbo, mantenlos una noche en una cocción de tamarindos (esto si la nodriza no padece de histeria; si padece, en lugar de tamarindos la infusión se hará en una cocción de achicoria o condrila, o de ambas); cuela y exprime; añade cuatro onzas de solución de rosas, de solución de violetas o de solución de rey; se prepara la bebida. Otra: toma cuatro dracmas de rosas disuelve en agua de achicoria, y añade tres onzas de solución de rosas o de rey; se prepara la bebida. Otra: toma seis dracmas de diacatolicon, disuelve en una cocción de flores cordiales y añade tres onzas de solución de rey, de rosas o de violetas; se prepara la bebida. Si la nodriza rehúsa las bebidas, adminístrensele las píldoras siguientes: se toma una dracma de píldoras agregativas, se forman cinco, se doran. Las úlceras o Aftas del niño se lavan con la cocción siguiente: cueces en agua agallas machacadas, con esta cocción, una vez colada, mezclas un poco de miel, cueces de nuevo hasta lograr una trabazón de miel, y aplicas el medicamento con el dedo frotando las úlceras; el procedimiento es de Aecio en el lugar citado. Galen. 6 de comp.med. emplea otro, que es como sigue: toma dos dracmas de cardenillo, cuatro dracmas de alumbre seco, un dracma de agallas reducidas a polvo, cier- 
nes todo con un lienzo, y con ello frotas las heridas. Muchos otros medicamentos aporta Gal., pero basten estos por lo que se refiere a la curación de las Aftas amarillas.

Las Aftas blanquecinas provienen de una leche excesivamente pituitosa, y esta, a su vez, de una sangre pituitosa. Se les ha de poner remedio con alimentos y medicamentos cálidos y secos, según enseñan Gal., 6 de comp. med. ph. per locos, y Avi., Fen. 6, 3, c. 23. Si la nodriza se encuentra en un estado saludable, se le administrarán los jarabes siguientes. Toma una onza de jarabe de borraja y otra de miel rosada y cuatro onzas de agua de hinojo, o una onza de culantrillos y otra de cortezas de cidra y cuatro onzas de agua escabiosa. Se emplean estos de acuerdo con la necesidad de quien los toma, y la cacoquimia pituitosa se purga como sigue. Toma una dracma de trociscos de agárico, mantenlos una noche en una cocción de mejorana o de hinojo o de pentaph; una vez colado, disuelve en ello tres dracmas de diafeno, dos onzas de jarabe resolutivo de rosas; se prepara la bebida. Si la nodriza prefiere píldoras, adminístrensele las siguientes. Toma una dracma de píldoras de agárico, se forman cinco, se doran; o bien, toma una dracma de píldoras indias. Si esto no parece bastante, el cuerpo afectado de cacoquimia se purgará de nuevo como sigue. Toma cuatro dracmas de electuario «indimino» dos dracmas de diacártamo, disuelve en una cocción escabiosa, y añade dos onzas de jarabe solutivo de rosas; se prepara la bebida. Simultáneamente las úlceras del niño se ungen con los medicamentos siguientes. Toma cuatro onzas de agallas cocidas, dos onzas de miel; la adición de hiel de tortuga es de gran eficacia, particularmente en niños, según dice Avic. en el lugar antes citado. Y si las úlceras son extraordinariamente corrosivas, hágase el lavado con una cocción de agallas y cadernillo o de agallas y balaustrias, por partes iguales, y una dracma de alumbre. Las agallas cocidas en vinagre son de una excepcional eficacia en toda úlcera corrosiva.

Las Aftas lívidas y negras requieren un método de curación distinto y no menos difícil que el de las otras, puesto que tienen peor origen. La nodriza presenta un exceso de humor melancólico; por ello produce una leche asimismo melancólica. Se nutrirá de alimentos cálidos y húmedos; puede comer, entre las hortalizas, buglosa, borraja, alcaparras, y estas hortalizas pueden cocerse con carne de cordero, gallina; deberá abstenerse de toda carne salada y de liebre; no tome café, leche, lacticinio alguno; sí perdiz, gallina, cabrito; de beber, agua de cinamomo, o de zarzaparrilla, o agua cocida con flor de borraja, de buglosa, o de lúpulos. Se le ha de extraer sangre, si el cuerpo se ve gravado por la exhuberancia de la nodri- 
za; la vena que hay que abrir es la interna de ambos brazos (respetando el orden señalado en la curación de las Aftas rojas: de los brazos si la menstruación ocurre a su tiempo y no falta; de los talones, en caso contrario, como allí se indicó); pero ábrase la vena perfectamente, para que salga la sangre más gruesa; y si la que sale es demasiado fina, se interrumpe la extracción, no sea que, eliminada ésta, permanezca la gruesa y sea causa de un mal mayor. Extraída la sangre de forma adecuada, empleará la nodriza jarabes frecuentes. Toma una onza de jarabe de borraja y otra de fumaria y tres onzas de lúpulos, o dos onzas de jarabe de rey y tres onzas de agua de borraja. Una vez controlado el humor convenientemente, se purga con la bebida que sigue. Toma cuatro dracmas del preparado medicamentoso hamech 5, tres onzas de jarabe solutivo de sen, en una cocción de sen; se prepara la bebida. O bien: toma cuatro dracmas de diasén, tres onzas de jarabe solutivo de rey, en una cocción de sen, epítimo y polipodio; se prepara la bebida. Si rechaza la bebida, tome las píldoras siguientes. Toma una dracma de píldoras de fumaria, se forman cinco y se doran. O bien: toma media dracma de píldoras agregativas, un escrúpulo de píldoras de «lapis labulis» se forman seis y se doran. Si tampoco puede tragar las píldoras, tome una hora antes de comer este medicamento. Toma tres onzas de conserva de rosas de Alejandría, un escrúpulo de polvo de sen, una gota de diagridio, mezcla; o que tome, ocho o diez días, en ayunas, cinco onzas de suero caprino en el que por la noche se tenga en infusión un escrúpulo de hojas de sen y a la mañana se cuele; adminístresele con un poco de azúcar.

En cuanto a las úlceras del niño, se lavan con el medicamento siguiente. T. Se prepara una mezcla de ambos alumbres, sal, agallas, cálices de bellota, nuez moscada, salvia y huesos de dátil con vinagre y miel, y se hace un linimento; y si se presentan Aftas negras, úsese con bastante frecuencia este medicamento, o el que sigue. T. Se trituran uvas pasas desgranadas y anís, se mezcla con miel, y se prepara un linimento.

\section{Capítulo III. Aftas causadas por fallo del vientre del lactante}

Hasta ahora hemos tratado de las Aftas que sobrevienen a los niños lactantes por causa de la nodriza. Podemos ya considerar qué tipo de cura se ha de seguir cuando la enfermedad procede del fallo del niño, cuando éste no elabora bien la leche, o porque su vientrecillo es demasiado débil, o porque succiona más cantidad de la que el vientrecillo puede lle- 
var. Entonces la leche se corrompe, adquiere por la corrupción acrimonia, y los vapores expulsados por el vientrecillo, dado que este cuece mal, suelen degenerar en fetidez y corrupción; estos vapores acres y mordaces, al llegar a la boca y paladar, producen ulceraciones o Aftas. Hay que curarlas no sin establecer distinciones, según enseñan Gal., 6, de comp. med. per locos, y Aecio en Tret. 2, serm. 4, c. 39. En efecto, lactantes y no lactantes pueden tomar alimentos o no tomarlos. Para los que toman alimentos son convenientes los medicamentos que les suelen propinar las mujeres en la comida, como es lenteja con un poco de pan, médula de ciervo o de ternera, y conviene mezclar con la comida algo de manzanas amargas, peras, nísperos; hay que añadir a veces algo de lechuga, achicoria y verdolaga, sobre todo cuando se trate de una ulceración inflamada. Pero, si el niño no toma más alimento que la leche de la nodriza, Gal. establece que es la nodriza misma la que ha de recibir la cura; ademạ́s la boca del niño será lavada con los remedios procedentes de los que más arriba hablamos; sin embargo, la cura no se ha de dirigir exclusivamente a la nodriza, sino que hay que corregir más bien el vientrecillo del niño, causa de las Aftas. Frótese éste con elementos caloríficos y corroborantes de sus fuerzas, tales como aceite nardino, ajenjo, aceite de Mathiolo, y rocíesele con polvo de ajenjo o de nuez moscada o rosa aromática tome el niño, lamiendo, jarabe de corteza de cidra o un poco de triaca o de mitrídato; póngasele supositorios para expulsar las heces; y si lo vemos propenso al vómito, provóquesele, aunque Aecio parece establecer lo contrario, tratra. 4 , serm. 1 , c. 75 , donde prescribe que no se provoque el vómito a los niños. Si el lactante se encuentra afectado sin que la nodriza padezca mal corporal alguno, Hip., 6, Epid., sect. 5, tex. 34, aconseja que se purgue a la nodriza, sea ésta o el niño la causa de las Aftas; suministrando el medicamento a la nodriza, lo suministra al niño; así dice: si la mujer o la cabra comen elaterio o cohombro silvestre, purga para el hijo. En ese paso exhorta Hip. a los médicos que cuidan un niño enfermo. a administrar el medicamento a sus madres.

\section{BIBLIOGRAFÍA}

Alonso Muñoyerro, L. (1945). La Facultad de Medicina en la Universidad de Alcalá de Henares. Madrid, p. 266.

Alvarez Sierra, J. (1967). Diccionario de Autoridades Médicas. Madrid, p. 401. 
Antonio, N. Bibliotheca Hispana Nova sive Hispaniorum Scriptorum qui ab anno MD ad MDCLXXXIV flouere notitia Tomo I. Madrid, p. 458.

Ballano, A (1807). Diccionario de Medicina y Cirugía o Biblioteca manual médico-quirúrgica Tomo VI. Madrid, p. 207.

Carreras Panchón, A. (1979). Pérez Cascales y la clínica del garrotillo. Asclepio. Vol. 3031. Madrid, p. 319-322.

Carles Genovés, C. (1983). Pérez Cascales, Francisco. En: LÓPEZ Piñero, J: M. ${ }^{a}$, Et als. Diccionario Histórico de la ciencia moderna en España, Tomo II. Barcelona, p. 158159.

Cascales Muñoz, J. (1931). El libro de los Cascales. Toledo, p. 141-55.

Chinchilla, A. (1845). Anales históricos de la Medicina en general y biográfico-bibliográficos de la espanola en particular. Tomo II. Valencia, p. 285-287.

Estrada Merina, A. (1963). Tres tratados pediátricos españoles del siglo Xvir. Cuadernos de Historia de la Medicina Española, Tomo II. Salamanca, p. 195-201.

GARCía LOPEZ, J. C. (1899). Biblioteca de escritores de la provincia de Guadalajara y bibliografía de la misma hasta el siglo XIX. Madrid, p. 430-432.

GARCÍA DEl ReAl, E. (1921). Historia de la Medicina en España. Madrid, p. 257-258.

Gómez-Menor Fuentes, J. (1973). Médicos toledanos del siglo de oro. Cuadernos de Historia de la Medicina Española. Salamanca, p. 382-383.

Granjel, L. S. Historia de la Pediatría Española. Salamanca, p. 33-42.

Granjel, L. S. (1978). La medicina española del siglo XVII. Salamanca, p. 27, 120, 167, 169, $178,179,200$ y 204.

HernÁNDEZ MoReJón, A (1850). Historia bibliográfica de la medicina española. Tomo IV. Madrid, p. 264-266.

López Piñero, J. M. y Bujosa Homar, F. (1982). Los tratados de enfermedades infantiles en la España del Renacimiento. Valencia, p. 133-154.

Pérez DE Escobar, A. (1776). Avisos médicos populares, y domésticos. Historia de todos los contagios. Madrid, p. 224.

Rico-Avello, C. (1956). Los clásicos del garrotillo. XV Congreso Intemacional de Historia de la Medicina. Madrid-Alcalá, p. 1-7.

SAnz, J. (1987). Historia de la Facultad de Medicina de Universidad de Sigüenza Guadalajara, p. 97-99.

SANz, J. La asistencia sanitaria del Cabildo catedralicio de Sigüenza. Sus médicos, cirujanos y boticarios. (Siglos XVI-XIX). Inédito. p. 75-77.

SANZ, J (1992). El Dr. Francisco Pérez Cascales, médico del Cabildo. Abside. N. ${ }^{\circ} 18$. Sigüenza, p. 16- 17.

Usandizaga, M. (1944). Historia de la Obstetricia y de Ginecología en España. Santander, p. 174-175.

Villalba, J. (1802). Epidemiología española o Historia cronológica de las pestes, contagios, epidemias y epizootias que han acaecido en España desde la venida de los cartagineses hasta el año de 1801. Tomo II. Madrid, p. 30-31. 


\section{NOTAS}

(1) Así lo afirman «revalorizando» el error, pues el dato no se comprobó: ALVAREZ sierra (2),Carles Genovés (6),. Cascales Muñoz (7), Chinchilla (8), Estrada Merina (9), Garcfa lópez (10), García del Real (11), López Piñero y Bujosa Homar (16), Usandizaga (22) y Villalba (23). Pérez de Escobar (17), natural de Sigüenza, habla de «mi paysano Cascales" pues conocería la vinculación de Pérez Cascales con el Cabildo catedralicio seguntino. El vocablo "paisano» en este caso, no creemos que tenga intención de precisar por parte del autor.

(2) En la obra de Pascual Madoz (1846), Diccionario Geográfico-Estadístico-Histórico de España y sus posesiones en ultramar, Tomo IV. Madrid, se define así este lugar: «BUGES: v. agregada al ayunt. de Meco ( $1 / 2$ leg.), en la prov. aud. terr. y e. g. de Madrid (7), part. jud. de Alcala de Henares (2), dioc. de Toledo (19): SIT. entre dos cerros, la combaten en general los vientos N. y S. y su clima produce algunas tercianas: tiene 5 casas algunos pozos de buen agua, y una igl. parr. (la Concepcion) servida por un párroco, cuyo curato es de entrada, y se provee en concurso general; en las afueras se encuentra un paseo pequeño con poco arbolado: confina el TERM. N. Villanueva de la Torre a $1 / 4$ leg. E. Camarma del Caño, a primera $1 \mathrm{Meco}$ a 1/2, y O. Azuqueca a primera, brota de el una fuente de buen agua con el titulo de Valdegallego. El TERRENO es de mediana calidad, y le atraviesa un arroyo del mismo nombre que la v. sigue su curso pasando por la pobl. al term. de Meco y desagua en el Nares. Sus CAMINOS dirigenn a los pueblos limitrofes. El CORREO se recibe de la adm. de la cab. de part. los martes, jueves.y sábados, y salen los mismos dias. PROD.: trigo, cebada, centeno y demas clases de granos y semillas, vino y aceite; mantiene ganado lanar y mular, cria caza de liebres y conejos; hay alguna pesca menor. POBL.: 3 vec. 16 alm. PROD.: 180.000 rs. IMP. 7.200. CONTR.: 451 rs. $18 \mathrm{mrs}$.

(3) Archivo Histórico Nacional, (A.H.N.) Sección Universidades. Universidad de Sigüenza. Libro de Actos y Grados. (Siq. 1260 F.). F. 273.

(4) A.H.N. Seccion Universidades. Universidad de Alcalá de Henares. Libro de Matriculas de 1574 a 1578. (Sig. 436 F.) s/p.:

En diez y nuebe de otubre -se refiere a 1574-

el ldo franco de guadalajara complutensis

En cursos posteriores aparece como francisco perez de guadalajara.

(5) Los libros de la Parroquia de la Concepción de la villa de Bugés pasaron a la de $\mathrm{N}^{\mathrm{a}}{ }^{\mathrm{S}}{ }^{\mathrm{a}}{ }^{\mathrm{a}}$ de la Concepción, de Meco, no conservándose en la actualidad más que uno de todos ellos y no es precisamente el que nos daría noticias de la inscripción bautismal de Francisco Pérez Cascales.

(6) A.H.N. Ibidem.

(7) Pérez Cascales, F. Liber de affectionibus puerorum. Ad lectorem. S/p.

(8) Alonso Muñoyerro (11). Pág. 266.

(9) Se encuentra en el A.H.N. Sección Universidades. Universidad de Alcalá. Legajo 35. 2. Expediente $n .^{\circ} 24$. El primer folio, que titula el expediente, dice así:

Processo de la cathedra menor de medicina que tenia El Dor $P .^{\circ}$ garcia y sobre las inabilidades quel Dr garçon a oppuesto a los Dhos guar ${ }^{a}$. y di ${ }^{\circ}$ Hernandez.

proueida Al Dor di fers.

Asclepio-Vol. XLVI-2-1994 
(10) Edito de la cathedra menor de Meda.

El dicho dia mes y año sobredhos - se refiere al 29 de agosto de 1586- habiendose propuesto Edito de la bacatura de la Cathedra de Medicina aue tenia El dor pero garcia carrero que baco por su esclusion a la cathedra de prima En tres dias del mes de otubre del dho año de sesenta y seys Con trno de diez dias fueron oppositores a la dha cathedra El Dor quadalajara Y Dor Dieqo Hernandez y como dho es dho dia veynteynuebe deste mes de otubre de mes y quios y ochenta y seys aos los ses Rector y Consos. juntos En la camara Rectoral pronunciaron por inabil y declararon Por tal inabil al dho dor quadalaiara, $Y$ Proueyeron la cathedra sobredha $A l$ dho Dor d $i^{\circ}$ Hernandez como consta en proceso de la dha cathedra y aun El dho dia El dho Dn di 9 Hernandez iuro El tenor de la constitucion sesenta y siete y El bedel $J U^{\circ}$ Rodriquez dio la posesion de la dha cathedra en el aula de medicina al dho dor dio fernandez y El dixo aue la Recibia Conforme a Constitucion Y Reformacion siendo El mro luis de sierra y Valtasar mnez mro de ceremonias y otros muchos. [A.H.N. Idem. Libro de Actos y Grados de 1582 a 1603. (Siq. 400 F.) F ${ }^{\circ}$ 100.]

(11) GÓMEZ-MENOR (11) Ibidem.

(12) Gómez-Menor (11). Cita la fuente: Archivo Histórico del Protocolo de Toledo. Leg. 10716. p. 126.

(13) Pérez Cascales, F. Op. cit. p. 61.

(14) Cfr. SANZ (20).

(15) Archivo de la Catedral de Sigüenza (A.C.S.) Libros de acuerdos y actas capitulares. Tomo 45. F. ${ }^{\circ} 192$

(16) A.C.S. Idem. $\mathrm{F}^{\circ} 233$

(17) Cfr. SANZ (21)

(18) A.C.S. Idem. Tomo 47. $\mathrm{F}^{\circ} 51$.

(19) Cfr. SANZ (19).

(20) SANZ (19). Pág. 99

(21) Ibidem.

(22) Fray Mateo de Burgos regentó la mitra seguntina durante los años de 1606 a 1611 y Antonio Venegas y Figueroa desde 1612 a 1614

(23) A.C.S. Idem. Tomo 46. $\mathrm{F}^{\circ} 200$ (Acta capitular de 24 de enero de 1611) y Tomo 47. $\mathrm{F}^{\circ} 155$ (Acta de 8 de octubre de 1614), respectivamente.

(24) A.C.S. Idem. Tomo 47. $\mathrm{F}^{\circ} 202$.

(25) Las afecciones estudiadas, con sus correspondientes capítulos son las siguientes: aftas bucales ( 3 capítulos), epilepsia (8), «estupor» o abolición completa de la sensibilidad y la motilidad, pústulas del cuero cabelludo (2), parálisis (2), rabia o espasmo cínico, hidrocefalia (2), tos (2), estornudos molestos (2), sanies o pus en los oídos, sanies o pus en los ojos, estrabismo (2), conjuntivitis, nubécula y cicatrices corneales (3), hipo (2), vómitos (2), tumefaccion del ombligo, supresion de la orina (5), cálculos urinarios (2), intértrigo, sabañones, viruela y sarampión (2) y lombrices y gusanos (3).

(26) Pérez Cascales, F. Op. cit. "Ad lectorem». S/p.

(27) La traduccion del latín fue realizada por el Prof. Marciano Somolinos a quien agradecemos éste y tantos testimonios de colaboración y amistad. 